\title{
Retraction: An Unusual Presentation of Acute Subdural Hematoma Secondary to Disseminated Intravascular Coagulation Following Conservative Management of Placenta Increta
}

\author{
Editorial Office
}

This retracts the Case Report article "An Unusual Presentation of Acute Subdural Hematoma Secondary to Disseminated Intravascular Coagulation Following Conservative Management of Placenta Increta", by Muhammad Fairuz Abdul Rahman et al, published in Vol. 9, No. 1, 2018, p34-36, doi: http://dx.doi. org/10.14740/jmc2989w.

This article is retracted by the authors and the Editorial Office, due to the duplicate submission involved in this article.

Manuscript submitted June 28, 2018, accepted September 27, 2018

Journal of Medical Cases Editorial Office. Email: editor@journalmc.org

doi: https://doi.org/10.14740/jmc2989wr 